\title{
Multiple evidence for widespread and general occurrence of type-III PHA synthases in cyanobacteria and molecular characterization of the PHA synthases from two thermophilic cyanobacteria: Chlorogloeopsis fritschii PCC 6912 and Synechococcus sp. strain MA19
}

\author{
T. Hai, S. Hein and A. Steinbüchel
}

Author for correspondence: A. Steinbüchel. Tel: +49 251 8339821. Fax: +49 2518338388. e-mail: steinbu@uni-muenster.de

Institut für Mikrobiologie, Westfälische WilhelmsUniversität Münster, Corrensstrasse 3, D-48149 Münster, Germany
Eleven different cyanobacteria were investigated with respect to their capabilities to synthesize poly-3-hydroxybutyrate [poly(3HB)] and the type of poly- $\beta$-hydroxyalkanoic acid (PHA) synthase accounting for the synthesis of this polyester. Several methods, including (i) Southern blot analysis using a phaCspecific DNA probe, (ii) Western blot analysis using specific polyclonal antiPhaE antibodies raised in this study against PhaE of Synechocystis sp. strain PCC 6803, (iii) generation and sequence analysis of PCR products using phaCspecific oligonucleotides as primers, and/or (iv) cloning and sequence analysis of PHA synthase structural genes, were used to provide evidence for the presence of a type-III PHA synthase in the following cyanobacteria:

Synechococcus sp. strains MA19 and PCC 6715, Chlorogloeopsis fritschii PCC 6912, Anabaena cylindrica SAG 1403-2, Cyanothece sp. strains PCC 7424, PCC 8303 and PCC 8801, and Gloeocapsa sp. strain PCC 7428. The screening was compared with corresponding studies using crude protein extracts and genomic DNA of Synechocystis sp. strain PCC 6803, as a positive control, which is so far the only cyanobacterium for which molecular data of the PHA synthase genes are available. No evidence for the presence of a type-III PHA synthase could be obtained for only three of the eleven investigated cyanobacteria (Stanieria sp. strain PCC 7437, Cyanothece sp. strain PCC 8955 and Gloeothece sp. strain PCC 6501). The entire PHA synthase structural genes of the two thermophilic cyanobacteria Synechococcus sp. strain MA19 and Chlorogloeopsis fritschii PCC 6912, and in addition a central region of the phaC gene of Cyanothece sp. strain PCC 8303, were cloned, sequenced and also heterologously expressed in Escherichia coli.

Keywords: inverse PCR, thermotolerant enzymes, PHB, bioplastic, Anabaena cylindrica, Gloeothece sp.

\section{INTRODUCTION}

Cyanobacteria are oxygenic, photoautotrophic prokaryotes which possess two photosystems (PSI and PSII)

Abbreviations: CDM, cell dry matter; PHA; poly(3-hydroxyalkanoate) PHB, poly(3-hydroxybutyrate); 3HB, 3-hydroxybutyrate; 3HV, 3-hydroxyvaleric acid.

The NCBI accession numbers for the phaC gene sequences reported in this paper are AY030295 (phaC $C_{\mathrm{MA} 19}$ ) and AF371369 (phaC $\left.C_{\mathrm{Cf}}\right)$. releasing electrons from water and which fix carbon dioxide via the Calvin-Benson-Bassham pathway. The fixed carbon is partially deposited in the form of intracellular polymers such as glycogen, other polyglucans and cyanophycin, which serve as carbon and energy reserves. The presence of poly(3-hydroxyalkanoate) (PHA) in about 50 strains of four different phylogenetic subsections of cyanobacteria has been reviewed by Vincenzini \& De Philippis (1999) (and literature cited therein). However, detailed studies on 
biosynthesis and accumulation of PHA have so far only been done for a few species of cyanobacteria, in particular for Chlorogloea fritschii (Carr, 1966; Jensen \& Sicko, 1971), Gloeocapsa sp. (Rippka et al., 1971), Oscillatoria limosa (Stal et al., 1990), Gloeothece sp. PCC 6909 (Arino et al., 1995), some species of the genus Spirulina (Vincenzini et al., 1990; De Philippis et al., 1992) and Synechococcus sp. strain MA19 (Miyake et al., 1996). So far, only 3-hydroxybutyrate (3HB) and 3hydroxyvaleric acid (3HV) from the various known constituents of PHAs (Steinbüchel \& Valentin, 1995; Steinbüchel, 2001) have been identified in the PHAs accumulated by cyanobacteria (Stal et al., 1990; De Philippis et al., 1992; Hein et al., 1998). The occurrence of the copolyester poly (3HB-co-3HV) was observed in Anabaena cylindrica 10C (Lama et al., 1996).

The biochemical and molecular basis of PHA synthesis has been investigated intensively in many microorganisms (Steinbüchel \& Hein, 2001). However, in cyanobacteria, studies at the molecular level regarding PHA biosynthesis have been reported only for Synechocystis sp. strain PCC 6803 (Hein et al., 1998; Taroncher-Oldenburg et al., 2000). Only from this cyanobacterium has the PHA synthase gene been cloned (Hein et al., 1998). Interestingly, the PHA synthase of Synechocystis sp. PCC 6803 is composed of two different subunits, encoded by two contiguous, adjacent cotranscribed genes, referred to as $p h a E$ and $p h a C$ (Hein et al., 1998). The translational products of these two structural genes showed similarity to the corresponding PHA synthases of the anoxygenic purple sulfur bacteria Allochromatium vinosum (Liebergesell \& Steinbüchel, 1992; Liebergesell et al., 1994), Thiocystis violacea (Liebergesell \& Steinbüchel, 1993), Thiococcus (formerly Thiocapsa)pfennigii (Liebergesell et al., 2000) and Ectothiorhodospira shaposhnikovii (Genbank accession no. AAG30259 for $p h a C$ and AAG30260 for phaE). These enzymes belong to the type-III PHA synthases characteristic of $\gamma$-Proteobacteria (Rehm \& Steinbüchel, 1999; Steinbüchel \& Hein, 2001). Expression of functionally active type-III PHA synthases requires the expression of both subunits $\mathrm{PhaE}$ and $\mathrm{PhaC}$; PhaE alone was completely inactive and $\mathrm{PhaC}$ alone exhibited only negligible activity, if at all (Liebergesell et al., 1994; Müh et al., 1999; Jia et al., 2000). The PhaC proteins exhibit much higher similarities than the PhaE proteins and the latter revealed absolutely no similarities to other PHA synthases, but contained two amino acid stretches at the C-terminal regions like PHA granule binding proteins (phasins), which might serve as binding domains of PHA synthases to the surface of PHA granules (Liebergesell et al., 2000). However, the function of PhaE has not yet been revealed.

Due to knowledge of only one cyanobacterial PHA synthase, it is still unclear whether the type-III PHA synthase is a unique enzyme of cyanobacteria, or whether other types (Rehm \& Steinbüchel, 1999) also occur in this group of photosynthetic bacteria. The aim of this study was to investigate the distribution of typeIII PHA synthases among cyanobacteria and to clone the pha genes from two thermophilic cyanobacteria. Thermotolerant PHA synthases have so far never been described and corresponding genes are not available. Such enzymes might be useful for biotechnological applications such as in vitro PHA biosynthesis processes (Steinbüchel, 2001).

\section{METHODS}

Bacterial strains and plasmids. An axenic culture of Synechococcus sp. MA19, which was also used in a previous study (Hai et al., 1999), was a gift of the culture collection of the Molecular Bioenergetics Laboratory at the National Institute of Bioscience and Human-Technology (Tzukuba, Ibaraki, Japan). Anabaena cylindrica SAG 1403-2 was obtained from the Sammlung von Algenkulturen Göttingen (Göttingen, Germany), whereas Chlorogloeopsis fritschii PCC 6912 and other axenic cyanobacteria used in this study were provided by Dr Rippka from the Pasteur Culture Collection (Institut Pasteur, Paris, France). The cyanobacteria, other bacterial strains and plasmids used in this study are listed in Table 1.

Media and cultivation conditions. Thermophilic and mesophilic cyanobacteria were grown photoautotrophically at 50 and $28^{\circ} \mathrm{C}$, respectively, in liquid BG11 medium (Rippka et al., 1979) with irradiation $\left(100 \mu \mathrm{E} \mathrm{s}^{-1} \mathrm{~m}^{-2}\right)$ and shaking (100 r.p.m.). To study PHA accumulation in cyanobacteria, two-stage cultivation experiments were done. The cultures were first grown in $500 \mathrm{ml}$ flasks containing $200 \mathrm{ml}$ full strength BG11 medium at 28 or $50^{\circ} \mathrm{C}$ with shaking under irradiation applying a photon flux of approximately $150 \mu \mathrm{E} \mathrm{m}^{-2} \mathrm{~s}^{-1}$. Since the doubling times of the strains studied differed, the second stage was carried out as follows. After 4 or $7 \mathrm{~d}$, when the cultures were in exponential growth phase, the medium was removed by centrifugation, the cell pellets were washed with sterile nitrogen-free medium (the sodium nitrate component was omitted; BG11o) and the cells were then resuspended in $50 \mathrm{ml}$ sterile BG11o medium containing $15 \mathrm{mM}$ acetate. PHA accumulation was promoted by incubating the cells at low irradiation (approx. $50 \mu \mathrm{E} \mathrm{m}^{-2} \mathrm{~s}^{-1}$ ) for a further $7 \mathrm{~d}$ with shaking. The medium volume was adjusted daily with sterile double-distilled water during cultivation.

Triclosan $\left(1-5 \mu \mathrm{g} \mathrm{ml}^{-1}\right)$ was added to the second phase when the cells had been transferred into BG11o medium plus $15 \mathrm{mM}$ acetate. For studying the influence of triclosan on PHA accumulation, a concentration of $1.5 \mu \mathrm{g}$ triclosan $\mathrm{ml}^{-1}$ was applied for all strains and growth was monitored for a further $7 \mathrm{~d}$.

Escherichia coli strains were grown with shaking (150 r.p.m.) at $37^{\circ} \mathrm{C}$ in Luria-Bertani (LB) medium (Sambrook et al., 1989) with or without antibiotics. Competent cells of Escherichia coli were prepared by using the standard $\mathrm{CaCl}_{2}$ method (Sambrook et al., 1989). For recombinant strains of Escherichia coli harbouring pha genes, PHA accumulation experiments were carried out in liquid LB containing $0.6 \%$ $(\mathrm{w} / \mathrm{v})$ glucose as carbon source. In addition, $50 \mu \mathrm{M}$ thiamine and $0.2 \mathrm{mM}$ IPTG were added if Escherichia coli harboured pBluescriptSK ${ }^{-}\left(\mathrm{pSK}^{-}\right)$or derivatives of this vector.

Preparation of PHA granules. PHA granules were isolated from acetate-grown cells of Synechocystis sp. PCC 6803 by centrifugation in a glycerol gradient as described previously (Hein et al., 1998). The PHA granules were enriched in the $65 \%(\mathrm{v} / \mathrm{v})$ glycerol fraction, which was confirmed by GC 
Table 1. Bacterial strains and plasmids used in this study

\begin{tabular}{|c|c|c|}
\hline Strain or plasmid & Genotype or phenotype characteristics* & Reference or source $\dagger$ \\
\hline \multicolumn{3}{|l|}{ Cyanobacteria } \\
\hline Anabaena cylindrica SAG 1403-2 & Growth at $28^{\circ} \mathrm{C}$ & SAG \\
\hline Chlorogloeopsis fritschii PCC 6912 & Optimal growth at $50{ }^{\circ} \mathrm{C}$ & PCC \\
\hline Cyanothece sp. strain PCC 7424 & Growth at $28^{\circ} \mathrm{C}$ & PCC \\
\hline Cyanothece sp. strain PCC 8303 & Growth at $28^{\circ} \mathrm{C}$ & PCC \\
\hline Cyanothece sp. strain PCC 8801 & Growth at $28^{\circ} \mathrm{C}$ & PCC \\
\hline Cyanothece sp. strain PCC 8955 & Optimal growth at $28{ }^{\circ} \mathrm{C}$ & PCC \\
\hline Gloeocapsa sp. strain PCC 7428 & Growth at $28^{\circ} \mathrm{C}$ & PCC \\
\hline Gloeothece sp. strain PCC 6501 & Growth at $28{ }^{\circ} \mathrm{C}$ & PCC \\
\hline Stanieria sp. strain PCC 7437 & Growth at $28^{\circ} \mathrm{C}$ & PCC \\
\hline Synechococcus sp. strain MA19 & Optimal growth at $50^{\circ} \mathrm{C}$ & Miyake et al. (1996) \\
\hline Synechococcus sp. strain PCC 6715 & Optimal growth at $50{ }^{\circ} \mathrm{C}$ & PCC \\
\hline Synechocystis sp. strain PCC 6803 & Growth at $28^{\circ} \mathrm{C}$ & PCC \\
\hline \multicolumn{3}{|l|}{ Escherichia coli } \\
\hline TOP10 & $\begin{array}{l}\text { recA1 endA1 gyrA96 thi-1 hsdR17 supE44 relA1 slac U169 } \\
\text { ( } 80 \text { lacZDM15) }\end{array}$ & Invitrogen \\
\hline XL-1 Blue & $\begin{array}{l}\text { recA1 endA1 gyrA96 thi-1 hsdR17 supE44 relA1 lac } \\
{\left[\mathrm{F}^{\prime} \text { proAB lacl }{ }^{\mathrm{q}} \mathrm{ZDM} 15, \operatorname{Tn} 10\left(\text { Tet }^{\mathrm{r}}\right)\right]}\end{array}$ & Stratagene \\
\hline S17-1 & thi1 proA hsdR17 hsdM+ recA RP4-tra-function & Simon et al. (1983) \\
\hline \multicolumn{3}{|c|}{ 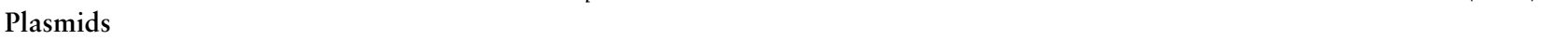 } \\
\hline $\mathrm{pSK}^{-}$ & amp lacZp/o, T7 \& T3 promoters & Stratagene \\
\hline $\mathrm{pMa} / \mathrm{c} 5-914$ & amp cat cI857ts lacZp/o, TIR, $\mathrm{P}_{\mathrm{L}} \& \mathrm{P}_{\mathrm{R}}$ & SK 6772 \\
\hline $\mathrm{pMa} / \mathrm{c} 5-914::$ EC1.1 & $\begin{array}{l}1 \cdot 1 \mathrm{kbp} \text { EcoRI-ClaI fragment of Synechocystis sp. PCC } 6803 \\
\text { harbouring } \mathrm{His}_{6} \text {-tagged } p h a E_{\mathrm{Syn}} \text { in } \mathrm{pMa} / \mathrm{c} 5-914\end{array}$ & This study \\
\hline pSK::phaC $C_{\text {MA19 }}$ & $1.3 \mathrm{kbp}$ PCR product of $\mathrm{PhaC}_{\mathrm{MA} 19}$ inserted in $\mathrm{pSK}^{-}$ & This study \\
\hline $\mathrm{pSK}:: p h a C_{\mathrm{Cf}}$ & $1.32 \mathrm{kbp}$ PCR product of $\mathrm{PhaC}_{\mathrm{MACf}}$ inserted in $\mathrm{pSK}^{-}$ & This study \\
\hline $\operatorname{pSK} A B_{\mathrm{Syn}}$ & $\begin{array}{l}\text { pSK }^{-} \text {harbouring } p h a A \text { and } p h a B\left(\text { phaA- } B_{\mathrm{Syn}}\right) \text { from } \\
\text { Synechocystis sp. PCC } 6803\end{array}$ & This study \\
\hline $\mathrm{pSK} A B C_{\mathrm{Cf}}$ & $\begin{array}{l}3 \cdot 6 \mathrm{kbp} \text { harbouring phaA }-B_{\mathrm{Syn}} \text { and } p h a C_{\mathrm{Cf}} \text { from } \\
\text { Chlorogloeopsis fritschii } \mathrm{PCC} 6912\end{array}$ & This study \\
\hline $\mathrm{pSK} A B C_{\mathrm{MA}}$ & $\begin{array}{l}3.6 \mathrm{kbp} \text { harbouring } p h a A-B_{\mathrm{Syn}} \text { and } p h a C_{\mathrm{MA} 19} \text { from } \\
\text { Synechococcus sp. MA19 }\end{array}$ & This study \\
\hline $\mathrm{pSK} A B E C_{\mathrm{Syn}}$ & $\begin{array}{l}\mathrm{pSK}^{-} \text {harbouring phaA, phaB, phaE and phaC from } \\
\text { Synechocystis sp. PCC } 6803\end{array}$ & This study \\
\hline
\end{tabular}

* Mesophilic and thermophilic cyanobacteria were cultivated at 28 and $50{ }^{\circ} \mathrm{C}$, respectively (the optimal temperature for growth was used). †PCC, Pasteur Culture Collection, Institut Pasteur, Paris, France; SAG, Sammlung von Algenkulturen Göttingen, Göttingen, Germany; SK, Culture Collection of the Institute of Microbiology, Münster, Germany.

analysis. The granule-bound proteins were analysed by Western immunoblotting.

DNA isolation and manipulation. Total DNA from the various cyanobacterial strains was extracted following a previously described protocol (Hein et al., 1998). Plasmid isolations were done by standard methods (Sambrook et al., 1989) or by using commercial kits (Qiagen). Restriction and ligation of DNA molecules were done according to standard protocols (Sambrook et al., 1989) or according to the instructions of the suppliers of the enzymes.

Southern hybridization experiments. The $p h a C_{\mathrm{Syn}}$ gene of Synechocystis sp. PCC 6803 was amplified by PCR, employing the primers Haphapcr1 and Haphapcr2 (Table 2) and Vent polymerase (New England Biolabs), according to the Biochemica PCR applications manual (1995). The PCR products (approx. $560 \mathrm{bp}$ ) were purified by using the Nucleotrap kit
(Macherey \& Nagel), following the instructions of the manufacturer, and were labelled by using the DIG-High Prime kit (Boehringer Mannheim). The hybridization, which was done at $53{ }^{\circ} \mathrm{C}$, and other related procedures followed standard methods (Sambrook et al., 1989). For visualizing the chemoluminescence, the substrate disodium 3-(4-methoxyspiro\{1,2dioxetane-3,2'(5'-chloro) tricyclo[3.3.1.1 $\left.1^{3,7}\right]$ decal $\left.\} 12-4-y l\right)$ phenyl phosphate (CSPD) was used.

Cloning of phaE ${ }_{\text {Syn }}$ and purification of $\mathrm{His}_{6}$-tagged $\mathrm{PhaE}_{\text {Syn }}$ from recombinant Escherichia coli. For cloning of $p h a E_{\mathrm{Syn}}$ into Escherichia coli, PCR was done by using HisphaE $\mathrm{Syn}_{\mathrm{Syn}}$ as sense and PhaEreverse as reverse primers (Table 2), which were deduced from the upstream and downstream regions, respectively, of slr1829 of Synechocystis sp. PCC 6803 (Kaneko et al., 1996). The $p h a E_{\mathrm{Syn}}$-specific PCR product obtained was purified and ligated into pMa/c5-914 (Table 1), which harbours, besides other genes, the $c \mathrm{I} 857$ ts gene encoding the 
Table 2. Primers used in this study

PCR primers for the cloning of $\mathrm{His}_{6}$-tagged $p h a E_{\mathrm{Syn}}$ with inserted restriction sites for NdeI and EcoRI (shown in italics). For cloning phaC from Synechococcus sp. MA19 and Chlorogloeopsis fritschii PCC 6912 the primers were deduced from the upstream and downstream regions of $p h a C$, except for the nucleotides shown in italics, which were inserted to generate BamHI and ApaI, and NdeI and BamHI restriction sites for the genes of strains MA19 and PCC 6912, respectively. PhaA and PhaB were obtained by PCR using sense and reverse primers pSKABsense and pSKABreverse. All primers were synthesized by MWG Biotech.

\begin{tabular}{|llc|}
\hline Primer & & Nucleotide sequence $\left(\mathbf{5}^{\prime} \rightarrow \mathbf{3}^{\prime}\right)$ \\
\hline HisphaE $_{\text {Syn }}$ & CATATGCATCACCATCACCATCACATGGAATCGACA & Overexpression \\
PhaEreverse & CTTAAGTACCACTTAATTGATAGGTAGCCTAGACTT & Overexpression \\
Haphapcr1 & GTTTTAATCGATTACGCNYTNGTNAAYMGNCCNTAYATG & phaC screening \\
Haphapcr2 & CGGGACTATRAADATCCAYTTYTCCATNCKTAGAAAGTT & phaC screening \\
MAphaCL & AAGTTGCTGAACTTTTTGCGCATG & Inverse PCR \\
MAphaCR & TGTAGCCGTTAATGTAGTCATCTAGA & Inverse PCR \\
PhaC69R & GCAGTTGGGCATTCAGAATACCTG & Inverse PCR \\
PhaC69L & ATATCCAGGCCCAACTTGAGAT & Inverse PCR \\
MaphaCsense & CAACTCCGGATCCAACAGATGAAG & Cloning of $p h a C$ \\
MaphaCreverse & GTCTCGAAAGGGCCCAACACAATC & Cloning of $p h a C$ \\
CfHisphaCs & TCTCCATATGCATCACCATCACCATCACGGCTGGAAATTTA & Cloning of $p h a C$ \\
CfphaCreverse & ATTCATAGGATCCCAGTTAAAAATGCGCT & Cloning of $p h a C$ \\
PhaABsense & AGCTTGAAATTTCCATATGCCCCGC & Overexpression \\
PhaABreverse & TTAGGATCCGTGGGCCCCTTTAC & Overexpression \\
\hline
\end{tabular}

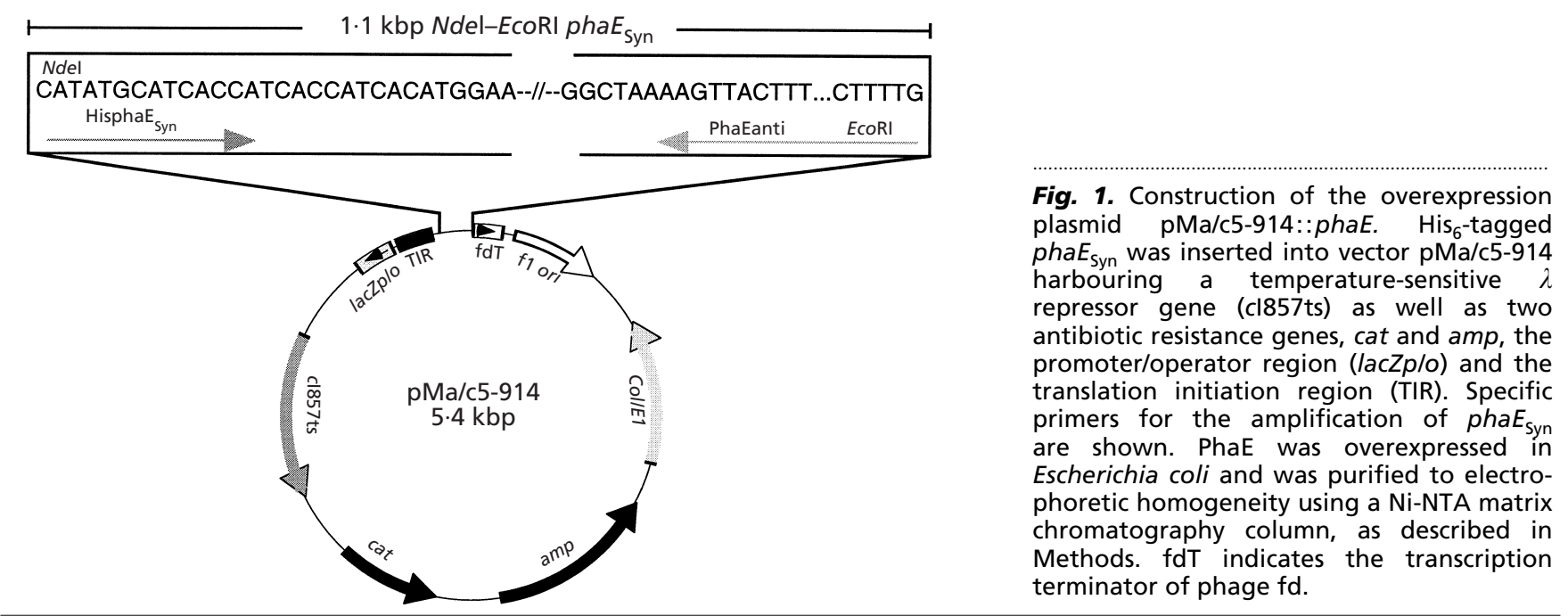

temperature-sensitive $\lambda$ repressor. The construction of the hybrid plasmid pMa/c5-914::EC1.1 is shown in Fig. 1. The $\mathrm{His}_{6}$-tagged protein, $\mathrm{PhaE}_{\mathrm{Syn}}$, was then expressed in Escherichia coli and was purified to electrophoretic homogeneity employing a Ni-NTA agarose-matrix purification kit following the instructions of the manufacturer (Qiagen).

Preparation of soluble protein cell fractions from recombinants Escherichia coli. The recombinant strains of Escherichia coli were grown with shaking in $200 \mathrm{ml} \mathrm{LB}$ medium plus ampicillin (final concentration $100 \mu \mathrm{g} \mathrm{ml} \mathrm{m}^{-1}$ ) to an $\mathrm{OD}_{600}$ of $0.5-0.7$ at $37^{\circ} \mathrm{C}$. Then IPTG $(0.2 \mathrm{mM})$ was added and the cells were cultivated for a further $4 \mathrm{~h}$. The washed cell pellets $(1 \mathrm{~g})$ were then resuspended in a buffer containing $20 \mathrm{mM}$ potassium phosphate, $500 \mathrm{mM}$ sodium chloride and $0.5 \mathrm{mM}$ EDTA and disintegrated by two passes through a French pressure cell at 10000 p.s.i. $(1$ p.s.i. $=6.9 \mathrm{kPa})$. The crude extract was obtained by centrifugation at $20000 \mathrm{~g}$ at $4{ }^{\circ} \mathrm{C}$ for $15 \mathrm{~min}$ and the protein concentration was adjusted to $1 \mathrm{mg} \mathrm{ml}^{-1}$.

Production and purification of antibodies against $\mathrm{PhaE}_{\mathrm{Syn}}$. The $\mathrm{His}_{6}$-tagged $\mathrm{PhaE}_{\mathrm{Syn}}$ was isolated from an SDS-polyacrylamide gel and submitted to Eurogentec for antibody production. The latter was achieved by three subcutaneous injections into a rabbit (animal code SA 6918; Eurogentec) over a period of 3 months following standard procedures. The antibodies were purified from the crude serum by using FPLC on a Protein A-Sepharose CL-4B affinity column (Hjelm et al., 1972).

Western blotting and immunodetection employing antiPhaE $_{\text {syn }}$ antibodies. Crude extracts were obtained from cells of cyanobacteria and recombinant Escherichia coli as follows. 
The washed cells (approx. $0 \cdot 2 \mathrm{~g}$ wet $\mathrm{wt}$ ) were dissolved in $1 \mathrm{ml}$ $10 \mathrm{mM}$ Tris/HCl buffer, $\mathrm{pH} 8 \cdot 0$, containing $5 \mathrm{mM}$ DTT, and subsequently disintegrated by $1 \mathrm{~min}$ treatment with a Sonoplus GM200 sonifier (Bandelin Electronic). Three volumes of this crude protein solution were then mixed with $1 \mathrm{vol}$. SDS-additive solution consisting of $8 \%(\mathrm{w} / \mathrm{v})$ SDS, $40 \%(\mathrm{w} / \mathrm{v})$ glycerol, $20 \%(\mathrm{v} / \mathrm{v})$ 2-mercaptoethanol and $0.004 \%(\mathrm{w} / \mathrm{v})$ bromophenol blue. The proteins were denatured by incubating at $95{ }^{\circ} \mathrm{C}$ for $5 \mathrm{~min}$. The proteins were then separated by SDS-PAGE in $11.5 \%(\mathrm{w} / \mathrm{v})$ polyacrylamide gels as described by Laemmli (1970). The protein bands from one gel were stained for proteins with Serva Blue R (Weber \& Osborn, 1969), whereas the proteins from a second gel were blotted onto a nitrocellulose BA83 membrane (Schleicher \& Schüll) using a semi-dry transfer blotter (Bio-Rad) and applying a voltage of $24 \mathrm{~V}$ for $100 \mathrm{~min}$. The membrane was then equilibrated with $10 \mathrm{mM}$ Tris/ $\mathrm{HCl}$ buffer, $\mathrm{pH} 8 \cdot 0$, containing $150 \mathrm{mM} \mathrm{NaCl}$ and $0.05 \%(\mathrm{v} / \mathrm{v}$ ) Tween 20 (TNT buffer) and blocked as described previously (Hein et al., 1998). The immunological detection followed a standard method (Sambrook et al., 1989) with the only modification that $5 \%$ $(\mathrm{w} / \mathrm{v})$ skimmed milk in TNT buffer was used as blocking agent. The purified antibodies, as eluted from the protein A Sepharose-4B column, were diluted 1:1000 and used as the primary antibody. A solution of an anti-rabbit immunoglobulin G-alkaline phosphatase conjugate (Sigma), diluted $1: 30000$, was used as the secondary antibody. After removing the excess of the secondary antibody by washing the membrane three times with TNT buffer containing $0 \cdot 1 \%(\mathrm{w} / \mathrm{v})$ bovine albumin fraction $\mathrm{V}$ and $0.1 \%(\mathrm{v} / \mathrm{v})$ Nonidet P40, the bound antibodies were visualized with nitroblue tetrazolium chloride (NBT) and 5-bromo-4-chloro-3-indolylphosphate (BCIP) with a commercially available detection kit (Sigma) following the instructions of the manufacturer.

PCR using degenerate primers. The nucleotide sequences of two primers, Haphapcr1 (sense) and Haphapcr2 (reverse), were deduced from highly conserved regions of superfamily phaC genes (Table 2), including phaC of the anoxygenic phototrophic bacteria Allochromatium vinosum and Thiocystis violacea, and the cyanobacterium Synechocystis sp. PCC 6803. The regions corresponded to amino acid positions 85-97 and 275-263, respectively, in PhaC of Synechocystis sp. PCC 6803.

PCR was performed with DNA isolated from various cyanobacteria by using Vent DNA polymerase and applying the following temperature programme: 1 cycle of $95^{\circ} \mathrm{C}$ for $2 \mathrm{~min}$, 30 cycles of $95^{\circ} \mathrm{C}$ for $30 \mathrm{~s}, 50^{\circ} \mathrm{C}$ for $30 \mathrm{~s}$ and $72^{\circ} \mathrm{C}$ for $80 \mathrm{~s}$. The PCR products were purified by using the Nucleotrap kit (Macherey Nagel) and were subsequently ligated to $\mathrm{pSK}^{-}$ DNA, which was linearized by treatment with EcoRV. The ligation products were then transformed into Escherichia coli following standard protocols (Sambrook et al., 1989).

Inverse PCR to clone the $5^{\prime}$ and $3^{\prime}$ regions of phaC and phaE from Synechococcus sp. MA19 and Chlorogloeopsis fritschii PCC 6912. To clone the $5^{\prime}$ and $3^{\prime}$ regions adjacent to the PCR products, inverse PCR (Triglia et al., 1988) was applied. Primers MAphaCL and MAphaCR (Table 2), corresponding to base positions 735-759 and 385-360 in $p h a C_{\text {MA19 }}$ (accession no. AY030295), respectively, were used for Synechococcus sp. MA19 DNA. Similarly, PhaC69R and PhaC69L (Table 2), corresponding to base positions 643-666 and 302-323 in phaC $_{\mathrm{Cf}}$ (accession no. AF371369), respectively, were used for the Chlorogloeopsis fritschii PCC 6912 template. The sequences of these primers were deduced from those of the $5^{\prime}$ and $3^{\prime}$ regions of the corresponding PCR products. Genomic
DNA was first restricted with PstI, cyclic products were then obtained by incubation with T4 DNA ligase and these were linearized by digestion with SspI. Using Vent polymerase, the following temperature programme was applied to both DNA templates: 1 cycle of $95^{\circ} \mathrm{C}$ for $2 \mathrm{~min}, 32$ cycles of successive programming of $95^{\circ} \mathrm{C}$ for $30 \mathrm{~s}, 57^{\circ} \mathrm{C}$ for $30 \mathrm{~s}$ and $72{ }^{\circ} \mathrm{C}$ for $2 \mathrm{~min}$. The PCR products were then precipitated by adding 2.5 vols ethanol, washed with $70 \%(\mathrm{v} / \mathrm{v})$ ethanol, dried at room temperature and dissolved in $20 \mu \mathrm{l} 5 \mathrm{mM}$ Tris $/ \mathrm{HCl}, \mathrm{pH} 8 \cdot 0$, containing $0.5 \mathrm{mM}$ EDTA. About $400 \mathrm{ng}$ PCR products were ligated at room temperature overnight with $400 \mathrm{ng}$ EcoRVlinearized $\mathrm{pSK}^{-} \mathrm{DNA}$ and were then transformed into Escherichia coli XL-1 Blue (see Fig. 3).

Cloning of phaC from Synechococcus sp. MA19 and Chlorogloeopsis fritschii PCC 6912. The phaC genes from both strains were amplified by PCR from genomic DNA following the procedures described above. The nucleotide sequences of the primers were deduced from the nucleotide sequences of regions located upstream and downstream of the corresponding $p h a C$ gene, but allowing the generation of BamHI and ApaI, or NdeI and BamHI restriction sites for the genes of strains MA19 $\left(p h a C_{\mathrm{MA} 19}\right)$ and PCC $6912\left(p h a C_{\mathrm{Cf}}\right)$, respectively. The primers MaphaCsense and MaphaCreverse were used for cloning $p h a C_{\mathrm{Ma} 19}$, whereas the primers CfHisphaCs with a $\mathrm{His}_{6}$ tag and CfphaCreverse were applied to clone $p h a C_{\mathrm{Cr}}$ (Table 2).

Construction of hybrid plasmids. To study PHA synthase activity of PhaC subunits some hybrid plasmids were constructed. The expression vectors were derived from $\mathrm{pSK}^{-}$as follows. (i) A PCR product containing slr1993, encoding $\beta$ ketothiolase $\left(p h a A_{\mathrm{Syn}}\right)$, together with slr1994, encoding acetoacetyl CoA reductase $\left(p h a B_{\mathrm{Syn}}\right)$, from Synechocystis sp. PCC 6803 was amplified by using primers PhaABsense and PhaABreverse, which included degenerate NdeI and BamHI restriction sites, respectively (Table 2). The purified PCR product $(2 \cdot 45 \mathrm{kbp})$ was cloned to obtain pSKABSyn (see Fig. 7). After digestion with $B a m \mathrm{HI}$, the purified $p h a A B_{\mathrm{Syn}}$ fragment was ligated to the BamHI-treated PCR product of pha $C_{\text {MA19 }}$ giving the phaABC fragment. (ii) The purified phaABC was ligated to EcoRV-digested $\mathrm{pSK}^{-}$. The hybrid plasmid obtained, pSKABC $\mathrm{MA}_{\mathrm{M} 19}$, was transformed into Escherichia coli XL-1 Blue. Similarly, other hybrid plasmids were constructed, such as $\mathrm{pSK} A B C_{\mathrm{Cf}}$ and $\mathrm{pSK} A B E C_{\mathrm{Syn}}$ containing fragment $p h a E C_{\mathrm{Syn}}$, which was obtained in a previous study (Hein et al., 1998). The hybrid plasmid pSKABEC $C_{\mathrm{svn}}$ was also transformed into Escherichia coli S17-1 and served in this study as a positive control.

DNA sequencing, sequence analysis and alignments. DNA sequences were determined employing a model 4000L DNA sequencer (LI-COR) and a thermosequenase fluorescencelabelled primer cycle sequencing kit (Amersham Life Science), according to the instructions of the respective manufacturer.

The nucleic acid sequences obtained from both strands were analysed with a computer program available from the Heidelberg Unix Sequence Analysis Resources (HUSAR, release 4.0). Sequence comparisons were performed by using the network service programs BLAST provided by the National Center for Biotechnology Information (NCBI). The sequences corresponding to C-terminal amino acids of $\mathrm{PhaE}$ and $\mathrm{PhaC}$, as well as the 120 aa of regions surrounding the substratebinding sites (Cys-149 in PhaC of Allochromatium vinosum) and the first 355 aa of PhaC, were aligned using the CLUSTAL $\mathrm{w}$ and also CLUSTAL $\mathrm{x}$ programs provided by the European Bioinformatics Institute. The phylogenetic distance 
tree was reconstructed by using PROTDIST and PROTPARS of PHYLIP (Phylogeny Inference Package; Felsenstein, 1989), which are available on the internet (http://www.es.embnet. org/Sevices/).

Electrophoresis of proteins and nucleic acids. SDS-PAGE of proteins was performed in $11.5 \%(\mathrm{w} / \mathrm{v})$ gels according to Laemmli (1970). Molecular mass marker proteins were purchased from Bio-Rad. Protein staining was done with Serva Blue R. Protein concentrations were estimated following the method of Bradford (1976). For analysis of nucleic acids, electrophoresis was done in 0.8 and $1.2 \%(\mathrm{w} / \mathrm{v})$ agarose gels according to standard methods (Sambrook et al., 1989).

Analysis of PHA. For quantitative and qualitative analysis of PHA, 5-7 mg lyophilized cells were subjected to methyl esterification (methanolysis) in a $1: 1(\mathrm{v} / \mathrm{v})$ chloroform/ methanol solvent mixture containing $15 \%$ (v/v) sulfuric acid. The resulting hydroxyacyl methylesters were analysed by GC as described by Timm et al. (1990). The retention times of authentic 3-hydroxy fatty acids were used for identification of PHA constituents.

Determination of PHA synthase activity. Determination of PHA synthase activity was done by a spectrometric assay with a $500 \mu \mathrm{l}$ assay mixture containing $25 \mathrm{mM}$ Tris/ $\mathrm{HCl}, \mathrm{pH} 7 \cdot 4$,

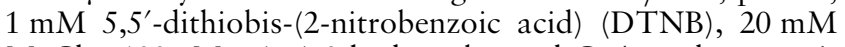
$\mathrm{MgCl}_{2}, 100 \mu \mathrm{M} \mathrm{D}(-)$-3-hydroxybutyryl-CoA and approximately $30 \mu \mathrm{g}$ protein from the soluble protein fraction of cells of Escherichia coli. The enzyme reactions were carried out at $30^{\circ} \mathrm{C}$ and the activity estimations followed the method described by Valentin \& Steinbüchel (1994).

\section{RESULTS AND DISCUSSION}

\section{PHA accumulation in cyanobacteria}

Physiological evidence for the presence of a PHA synthase in the investigated cyanobacteria was obtained by two-stage cultivation of 10 different strains of cyanobacteria in BG11 and in nitrogen-free BG11o medium containing acetate. Among them only two fastgrowing strains of Synechococcus sp. PCC 6715 and Synechococcus sp. MA19 reached exponential growth phase after $4 \mathrm{~d}$. Eight strains accumulated poly $(3 \mathrm{HB})$ at levels ranging from 0.7 to $6.5 \%(\mathrm{w} / \mathrm{w})$ of cell dry matter (CDM). For Cyanothece sp. strains PCC 8955 and PCC 8801 only trace amounts of poly $(3 \mathrm{HB})$ were determined (Table 3). In the absence of acetate, the poly $(3 \mathrm{HB})$ content of these strains was negligible or even undetectable (data not shown). The thermophilic cyanobacteria Synechococcus sp. MA19 and Chlorogloeopsis fritschii PCC 6912, which grew optimally at $50{ }^{\circ} \mathrm{C}$, accumulated by far the highest amounts (approx. 6.5 and $6.2 \%, w / w$, of CDM, respectively) of poly $(3 \mathrm{HB})$. Transmission electron micrographs of thin sections revealed typical poly $(3 \mathrm{HB})$ granules with monolipid boundary layers in acetate-grown cells of both thermophilic cyanobacteria (data not shown). If the bacteriocide triclosan, known to be an inhibitor of fatty acid de novo synthesis (Hoang \& Schweizer, 1999), was applied to the acetate-growing cultures at a concentration of $1.5 \mu \mathrm{g} \mathrm{ml}^{-1}$, neither the content, the composition of the accumulated PHA (Table 3 ) nor the fatty acid profiles of the methanolized cells were significantly affected (data not shown). At this concentration triclosan did not affect growth of almost all strains studied, with the exception of Cyanothece sp. strains PCC 8303 and PCC 8801, which exhibited chlorosis of the cells after $72 \mathrm{~h}$ incubation. Triclosan was also tested at concentrations up to $5 \mu \mathrm{g} \mathrm{ml}^{-1}$. However, at a concentration of $2.5 \mu \mathrm{g} \mathrm{ml}^{-1}$ or higher it caused chlorosis and cell lysis of the cyanobacteria studied. Thus, acetate is directly metabolized to acetyl-CoA and further to poly (3HB), probably employing the Ralstonia eutropha

Table 3. Growth and PHA accumulation in cyanobacteria cultivated in acetate medium with and without triclosan added

Experiments were done in triplicate and the mean values are provided with standard errors $(P<0 \cdot 05)$. Two-stage cultivation experiments are described in Methods. In the absence of acetate the cells accumulated negligible (trace, TR) or undetectable (ND) amounts of PHA.

\begin{tabular}{|c|c|c|c|c|}
\hline \multirow[t]{2}{*}{ Strain } & \multicolumn{2}{|c|}{$\mathrm{PHB}(\%, \mathrm{w} / \mathrm{w}$, of CDM $)$} & \multicolumn{2}{|c|}{ Effect of triclosan $\left(1.5 \mu \mathrm{g} \mathrm{ml}^{-1}\right)$} \\
\hline & BG11o & + Acetate & Chlorosis* & PHB $(\%, w / w$, of CDM $)$ \\
\hline Chlorogloeopsis fritschii PCC 6912 & TR & $6 \cdot 2 \pm 1 \cdot 5$ & - & $6 \cdot 7 \pm 1 \cdot 0$ \\
\hline Cyanothece sp. PCC 7424 & TR & $1 \cdot 1 \pm 0 \cdot 1$ & - & $0 \cdot 5 \pm 0 \cdot 1$ \\
\hline Cyanothece sp. PCC 8303 & $0 \cdot 3 \pm 0 \cdot 1$ & $2 \cdot 7 \pm 0 \cdot 5$ & + & $3 \cdot 3 \pm 0 \cdot 2$ \\
\hline Cyanothece sp. PCC 8801 & ND & TR & + & TR \\
\hline Cyanothece sp. PCC 8955 & $\mathrm{ND}$ & TR & - & TR \\
\hline Gloeocapsa sp. PCC 7428 & $<0 \cdot 3$ & $1 \cdot 5 \pm 0 \cdot 1$ & - & $1 \cdot 2 \pm 0 \cdot 2$ \\
\hline Gloeothece sp. PCC 6501 & $\mathrm{TR}$ & $1 \cdot 4 \pm 1 \cdot 0$ & - & $1 \cdot 0 \pm 0 \cdot 1$ \\
\hline Stanieria sp. PCC 7437 & TR & $0 \cdot 9 \pm 0 \cdot 5$ & - & $0 \cdot 8 \pm 0 \cdot 1$ \\
\hline Synechococcus sp. MA19 & $0 \cdot 5 \pm 0 \cdot 2$ & $6 \cdot 5 \pm 2 \cdot 5$ & - & $6 \cdot 8 \pm 0 \cdot 5$ \\
\hline Synechococcus sp. PCC 6715 & ND & $0.7 \pm 0 \cdot 5$ & - & $0 \cdot 5 \pm 0 \cdot 2$ \\
\hline
\end{tabular}

*Triclosan at a concentration of $1.5 \mu \mathrm{g} \mathrm{ml} \mathrm{m}^{-1}$ did $(+)$ or did not $(-)$ affect growth of the cyanobacteria studied. 
Table 4. Four approaches for identification of PHA synthases in cyanobacteria applied in this study

+ , Detectable amounts of poly $(3 \mathrm{HB})$ or positive reaction; - , trace amount of poly $(3 \mathrm{HB})$ or negative reaction; ND, not determined. The experiments were carried out in triplicate and followed the protocols described in Methods.

\begin{tabular}{|c|c|c|c|c|}
\hline Strain & $\begin{array}{c}\operatorname{Poly}(3 \mathrm{HB}) \\
\text { accumulation }\end{array}$ & $\begin{array}{l}\text { Southern blot } \\
\text { (phaC probe) }\end{array}$ & $\begin{array}{l}\text { Western blot } \\
\left(\text { anti-PhaE }_{\mathrm{Syn}}\right)\end{array}$ & $\begin{array}{c}\text { PCR product } \\
(\mathrm{bp})\end{array}$ \\
\hline Anabaena cylindrica SAG 1403-2* & + & + & - & 600 \\
\hline Chlorogloeopsis fritschii PCC 6912 & + & + & + & 555 \\
\hline Cyanothece sp. PCC 7424 & + & ND & + & - \\
\hline Cyanothece sp. PCC 8303 & + & + & + & 550 \\
\hline Cyanothece sp. PCC 8801 & - & - & + & ND \\
\hline Cyanothece sp. PCC 8955 & - & ND & - & - \\
\hline Gloeocapsa sp. PCC 7428 & + & ND & - & - \\
\hline Gloeothece sp. PCC 6501 & + & - & - & ND \\
\hline Stanieria sp. PCC 7437 & + & ND & - & - \\
\hline Synechocystis sp. PCC $6803^{*}$ & + & + & + & 560 \\
\hline Synechococcus sp. MA19 & + & - & + & 565 \\
\hline Synechococcus sp. PCC 6715 & + & - & + & 600 \\
\hline
\end{tabular}

*PHA accumulation in Anabaena cylindrica SAG 1403-2 and Synechocystis sp. PCC 6803 was reported by Vincenzini \& De Philippis (1999) and Hein et al. (1998).

biosynthetic pathway using $\beta$-ketothiolase and acetoacetyl-CoA reductase. Evidence for this was recently obtained by a different approach (TaroncherOldenburg et al., 2000).

\section{Southern hybridization with the $p h a C_{\text {syn }}$ DNA probe}

In further experiments we screened the genomes of the investigated cyanobacteria for the presence of PHA synthase structural genes and for the specific type of PHA synthase synthesized using various methods. A first approach to investigate the distribution of type-III PHA synthases in PHA-accumulating cyanobacteria was Southern hybridization. We focused on the type-III PHA synthase because Synechocystis sp. PCC 6803, which is the only cyanobacterium in which PHA synthase genes have already been identified, possesses this type of enzyme (Hein et al., 1998). Cyanobacterial total genomic DNA of six strains was digested separately using PstI, EcoRV or BamHI and the DIG-labelled PCR product containing the Synechocystis sp. PCC 6803 PHA synthase structural gene $\left(p h a C_{\text {Syn }}\right)$ was employed as DNA probe. In addition to the six strains studied above, the poly(3HB)-accumulating cyanobacteria Anabaena cylindrica SAG 1403-2 and Synechocystis sp. PCC 6803 were also investigated. The results are summarized in Table 4. In addition to the positive control (Synechocystis sp. PCC 6803) only three genomes revealed a positive signal: Anabaena cylindrica SAG 1403-2, Chlorogloeopsis fritschii PCC 6912 and Cyanothece sp. PCC 8303, whereas the genomic DNA fragments of the other four strains gave no signals (Table 4). Since three of the latter were able to accumulate poly $(3 \mathrm{HB})$ and must therefore possess PHA synthase structural genes, the absence of hybridization might be caused either by differences in the codon usage in the phaC genes of these strains as compared to that of Synechocystis sp. PCC 6803 or by the presence of a different type, or at least a less similar, PHA synthase.

\section{Screening for PhaE-containing strains using His $_{6}$-tagged $\mathrm{PhaE}_{\text {syn }}$ antibodies}

One further approach was the application of Western immunoblotting using crude extracts of the various cyanobacteria and antibodies raised against various PHA synthases. Antibodies raised against the type-I and type-III PHA synthases from $R$. eutropha $\left(\mathrm{PhaC}_{\mathrm{Re}}\right)$ and Allochromatium vinosum $\left(\mathrm{PhaC}_{\mathrm{Av}}\right)$, respectively (Liebergesell et al., 1994), gave no cross-reaction with the samples investigated in this study putatively containing cyanobacterial PHA synthases (data not shown and Hein et al., 1998).

We therefore purified the PHA synthase PhaE from Synechocystis sp. PCC 6803 ( $\left.\mathrm{PhaE}_{\mathrm{Syn}}\right)$. A His ${ }_{6}$-tagged phaE $E_{\text {Syn }}(1 \cdot 1 \mathrm{kbp})$ construct was made and expressed in Escherichia coli TOP10 under the control of $P_{\mathrm{L}}$ and $P_{\mathrm{R}}$ of the $\lambda$ promoter of plasmid $\mathrm{pMa} / \mathrm{c} 5-914$, the construction of which is shown in Fig. 1. The fusion protein was purified by affinity chromatography on an Ni-NTA column followed by SDS-PAGE. PhaE ${ }_{\text {Syn }}$, which was eluted from the SDS-polyacrylamide gel, was verified by N-terminal amino acid sequence analysis and was submitted for antibody production. The polyclonal antibodies raised against $\mathrm{PhaE}_{\mathrm{Syn}}$ were purified from rabbit serum as described in Methods.

Western blotting using the anti-PhaE $\mathrm{Sun}_{\mathrm{Syn}}$ antibodies was performed with protein crude extracts from 12 strains of cyanobacteria, including Synechocystis sp. PCC 6803. 
As reference samples a crude extract of recombinant Escherichia coli expressing $P h a E_{\mathrm{Syn}}$ and proteins solubilized from poly(3-hydroxybutyrate) (PHB) granules of Synechocystis sp. PCC 6803 (Hein et al., 1998) were applied. Specific cross-reactions occurred with a $37 \mathrm{kDa}$ protein in the crude protein fraction of Synechocystis sp. PCC 6803, in the PHB granule protein extract and in the recombinant Escherichia coli extract. In addition, crude extracts from Synechoccocus sp. MA19, Chlorogloeopsis fritschii PCC 6912 and Cyanothece PCC 8303 gave weak signals, each corresponding to a $40 \mathrm{kDa}$ protein band. Moreover, two signals occurred at 36 and $40 \mathrm{kDa}$ in Cyanothece sp. strains PCC 7424 and PCC 8801, and also in Synechococcus sp. PCC 6715 (Table 4). It remains to be analysed whether these three latter cyanobacteria possess two PhaE subunits of different molecular masses, or whether the $36 \mathrm{kDa}$ protein is a proteolysis product of the $40 \mathrm{kDa}$ protein. Crude extracts from the following cyanobacteria did not reveal any protein cross-reaction with the anti-PhaE $\mathrm{S}_{\mathrm{Syn}}$ antibodies: Anabaena cylindrica SAG 1403-2, Cyanothece sp. PCC 8955, Gloeothece sp. PCC 6501, Gloeocapsa sp. PCC 7428 and Stanieria sp. PCC 7437 (Table 4). It is remarkable that Anabaena cylindrica SAG 1403-2 obviously contains phaC according to hybridization with the $p h a C$-specific probe, but seems to lack PhaE according to the result of the Western blotting experiment. Since this strain is similar to Anabaena cylindrica 10C (Lama et al., 1996), as indicated by the accumulation of poly (3HB-co-3HV) (Vincenzini \& De Philippis, 1999), PhaE or a homologous protein might be more diverse among the strains studied.

In conclusion, these immunological studies provide further evidence for the widespread distribution of typeIII PHA synthases in the cyanobacterial strains investigated in this study. As mentioned above, the antibodies against $\mathrm{PhaC}_{\mathrm{Re}}$ and $\mathrm{PhaC}_{\mathrm{Av}}$ did not reveal cross-reaction with $\mathrm{PhaC}_{\mathrm{Syn}}$. Therefore, it is clearly shown that antibodies raised against the more specific and typical components are suitable to screen for the distribution of type-III PHA synthases among cyanobacteria and probably also in other bacteria.

\section{Screening cyanobacterial genomes for phaC by using PCR}

A third approach used to investigate the occurrence and distribution of type-III PHA synthases in cyanobacteria employed PCR using genomic DNA of the various cyanobacteria as template and oligonucleotides specific for the $p h a C$ gene as primers. For this, the nucleotide sequences of the oligonucleotides were designed according to a highly conserved region of the $\mathrm{PhaC}$ superfamily. PCR products were obtained for Chlorogloeopsis fritschii PCC 6912 (555 bp), Synechococcus sp. MA19 (565 bp), Cyanothece sp. PCC 8303 (550 bp), Anabaena cylindrica SAG 1403-2 (approx. $600 \mathrm{bp}$ ) and Synechococcus sp. PCC 6715 (approx. $600 \mathrm{bp}$ ). The sizes of the first three PCR products were verified by DNA sequencing, whereas the sizes of the last two products were determined by $1 \cdot 2 \%(\mathrm{w} / \mathrm{v})$ agarose gel electrophoresis only. A fragment of the expected size of 560 bp was obtained for Synechocystis sp. PCC 6803, which again served in this study as a positive control. The minor variations in the sizes of the PCR products were not only caused by the individual nucleotide sequences of templates, but also by the positions where the degenerate primers hybridized.

The amino acid sequences deduced from the nucleotide sequences of the PCR products of Chlorogloeopsis fritschii PCC 6912, Cyanothece sp. PCC 8303 and Synechococcus sp. MA19 exhibited 76, 83 and $75 \%$ identity, respectively, with the corresponding regions of $\mathrm{PhaC}_{\mathrm{Syn}}$. Alignment of these sequences, using CLUSTAL W (1.81) software of the European Bioinformatics Institute (http://www2.ebi.ac.uk), showed striking homologies not only to amino acid sequences of the $\mathrm{PhaC}$ proteins of other type-III PHA synthases, but also to those of type-I and type-II PHA synthases, such as PhaC of $R$. eutropha and PhaC1 of $P$. aeruginosa, respectively. These regions are considered as the covalent substrate binding regions, containing conserved cysteine residues corresponding to positions Cys-130 and Cys-149 in PhaC from Allochromatium vinosum, as shown recently by Jia et al. (2000). It is remarkable that these regions also contain a highly conserved Cys-157 residue and a stretch of amino acids typical for cyanobacteria that does not occur in the typeIII PhaC proteins of anoxygenic photosynthetic bacteria. We have therefore termed this the cyanobacterial box (see Fig. 2). This region is different from the corresponding sequences of all other type-III PHA synthases and also from type-I and type-II PHA synthases.

\section{Cloning of the pha loci of the thermophilic cyanobacteria Synechococcus sp. MA19 and Chlorogloeopsis fritschii PCC 6912}

The two thermophilic cyanobacteria, represented by the unicellular strain Synechococcus sp. MA19 and the heterocystous branching filamentous strain Chlorogloeopsis fritschii PCC 6912, were the most active PHAaccumulating strains (Table 3) and must obviously possess thermotolerant PHA synthases, which have been so far unavailable and which are of interest for various biotechnological applications. Therefore, all further studies focused on these PHA synthases. We applied inverse PCR to clone the entire PHA synthase structural genes from Synechococcus sp. MA19 and Chlorogloeopsis fritschii PCC 6912. Genomic DNA isolated from these two cyanobacteria was digested with restriction enzymes EcoR V, Bam HI and PstI, which do not cleave in slr1829 (phaE) and slr1830 (phaC) of Synechocystis sp. PCC 6803 (Kaneko et al., 1996; Hein et al., 1998). It was therefore unlikely that these restriction enzymes would have recognition sites close to the PCR products obtained above. The DNA fragments were subsequently religated using T4 DNA ligase and the recycled DNA molecules were then digested by $S s p \mathrm{I}$, for which there is a unique site in the previously sequenced 
Cys-149 (A. vinosum)

$R$. eutropha

P.aer ( $\mathrm{PhaC} 1$ )

A.vinosum

T. violacea

T.pfennigii

E. shaposhk.

Cyanothece

Synech. MA19

C.fritschii

Syn. PCC 6803

Consensus

R. eutropha

P.aer (PhaC1)

A. vinosum

T.violacea

T.pfennigii

E. shaposhk.

Cyanothece

Synech. MA19

C.fritschij

Syn. PCC 680

Consensus

IVSWRNPDA SMAGSTWDDYIEHAAIRAIEVARDISGODKINVLGFCVGGTIVSTALAVLA 333 IVSWRNP'TKSOREWGLTTYIEALKE-AIEVVLSITGSKDLNLLGACSGGITTATIVGHYV 311 LIDWGYPDQGDRALTLDDYINGYIDRCVDYLREAHGVDKVNLLGICQGGAFSLMY SALHP 163 LIDWGYPDQADSALTLDDYINGYIDSCVDYLCETHEVDQVNILGICQGGAFSLMYASLHP 162 LIDWGYPDOADRALTLDDYINGYIDRCVDYLRETHGVDOV-LLGICQGGAFSLCYTALHS 163 LIDWGYPDRADRFLTMDDYLNGYLDRCVDE ICRRHNLDKINILGICOGG'TFSLCY SAMHP 162 LIDWGYPGRGDRWLTLDDYINGY LNNCVDFIRASHQLDKVNLLGICQGGTFSLCYSSLYP 069 LIDWGYPTRADRWLTLDDYINGY INNCVDFIRKKHDILLKINLLGICQGGTFSLCYSAIYP 165 LIDWGYPGRGDRWLTLDDYINGYLNNCVDFIRTSHQLLKVNLLGICQGGTFSLCYSSLYP 167 LIDWGYPSRGDRWLTLEDYLSGYLNNCVDI ICQRSQQHKTTLUGVCQGGTESICCASLFP 178

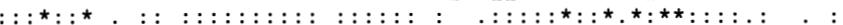

APAASVTLLTTLLDFADTGILDVFVDEGHVQLREATLGGGAGAPCALLRGLELANTESFL 393 AKV-NAFTOLVSVLDFELNTOVALFADEKTLEAAKRRSYOSGVLE-GKKD-MAKVFAVMR 368 DKVRNLVTMVT PVDFKTPDNLLSAW------VONVDIDLAVDTMGN I PGELLNWTFLSLK 217 DKVKNLVTMVT PVDFKT PGNLLSAW------VQNVDIDLAVDTMGNIPGELLNWTFLSLK 216 EKVKNLVTMVTPVDFQTPGNLLSAW------VQNVDVDLAVDTMGNI PGELLNWTFLSLK 217 EKVQNLITMVTPVDFQTPDNILSHW------VKHVDIDTLVDTMGNVPGELLNWTFLNLK 216 DKVNNLVVMVAPVDFHOPETLLNMRGGCTLGAEA IDVDLMVDALGNI PGDFLNLE FLMLK 129 EKVKNLIVMVTPVDFQISDSLLYMRGGCTLGAEA LDIDLMVDCLGNI PGDFLNFEFLMLK 225 DKVNNLVVMVAPVDFHQPETLLNM RGGCTLGAEA IDVDLMVDALGNI PGDFLNLEFLMLK 227 DKVKNLVVMVAPVDEEQPGTLLNARGGCTLGAEAVDIDLMVDAMGNIPGDYLNLEFLMLK 238

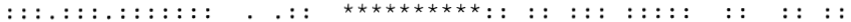

$\downarrow$

Cyanobacterial box
Fig. 2. Similarities and differences of deduced amino acid sequences of the substrate covalent binding site of PHA synthases. The substrate-binding site, corresponding to Cys-149 of Allochromatium vinosum, of various PhaC proteins of all three types of PHA synthases were aligned by using CLUSTAL W software. Here, the partial primary structure of Synechococcus sp. MA19, Chlorogloeopsis fritschii PCC 6912, Cyanothece sp. PCC 8303, Synechocystis sp. PCC 6803, Ectothiorhodospira shaposhnikovii and of three purple sulfur bacteria, Allochromatium vinosum, Thiocystis violacea and Thiococcus pfennigii, were analysed. As representatives of type-I PHA and type-II PHA synthases the corresponding regions of $\mathrm{PhaC}$ from $R$. eutropha and PhaC1 from Pseudomonas aeruginosa were co-aligned. In the highly conserved region $\left(^{*}\right)$ of the PhaC subunits of cyanobacteria the 'cyanobacterial box' is indicated. Absolute conservation, high conservation and low conservation are indicated by '*', ':' and '.', respectively.
Genomic DNA

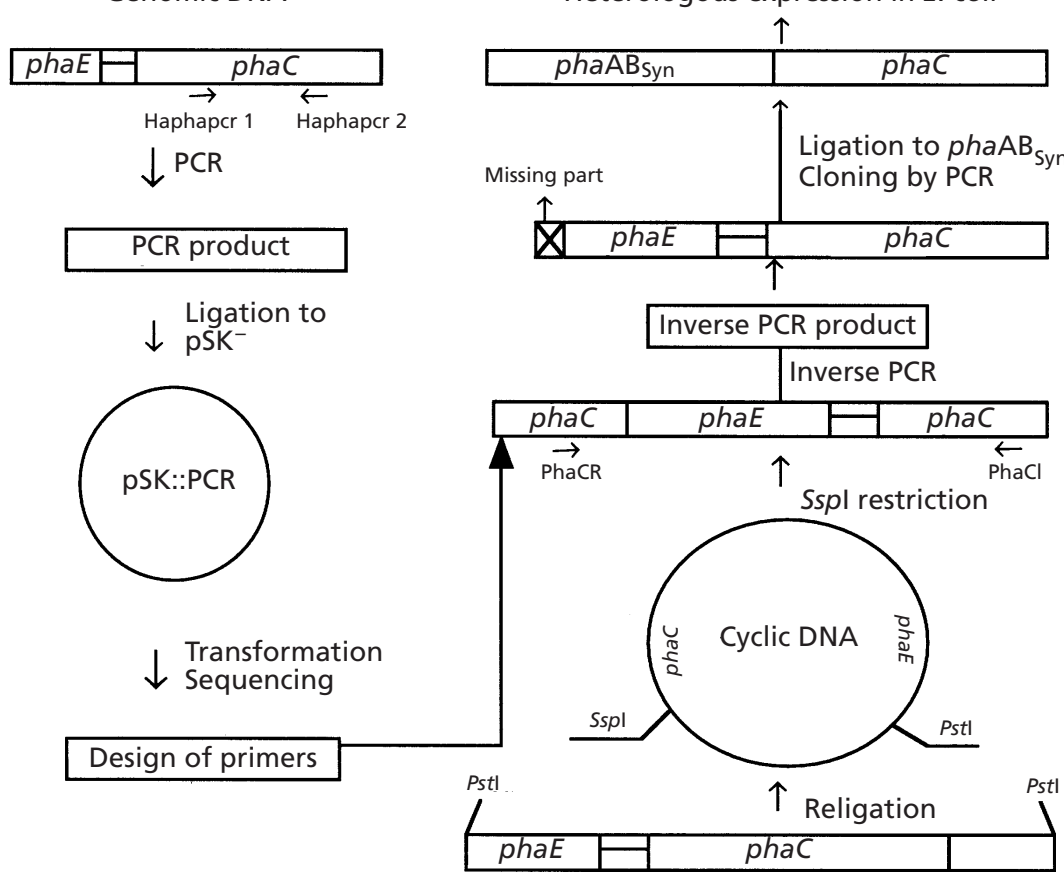

Heterologous expression in $E$. coli
Fig. 3. Flow diagram describing the procedure to clone phaE and phaC from the two thermophilic cyanobacteria. Primer sequences are shown in Table 2.
PCR products. These template DNA molecules were used in combination with the primers given in Methods (see Table 2). Inverse PCR was successful only for the PstI-digested DNA of strains MA19 and PCC 6912 and gave products of 2250 and $2430 \mathrm{bp}$, respectively. The inverse PCR products were ligated to EcoRV-restricted pSK ${ }^{-}$DNA, transformed into Escherichia coli XL-1 Blue and were subsequently sequenced. The PCR procedures employed are shown in Fig. 3. The DNA sequences obtained were analysed by the computer programs HUSAR and BLAST as described in Methods.
Two ORFs, corresponding to $\operatorname{slr} 1830\left(p h a C_{\text {Syn }}\right)$ and slr1829 ( $\left.p h a E_{\text {Syn }}\right)$, were identified in the inverse PCR products obtained with Chlorogloeopsis fritschii PCC 6912 and Synechococcus sp. MA19 template DNA. Both genes were separated by intragenic regions of 165 and $93 \mathrm{bp}$ in the genomes of strains PCC 6912 and MA19, respectively. Unfortunately, both $5^{\prime}$ regions of the phaE genes of strains MA19 (phaE $\left.\mathrm{MA19}_{\mathrm{M}}\right)$ and PCC 6912 $\left(p h a E_{\mathrm{Cf}}\right)$ possessed a restriction site for PstI. Therefore, approximately 100 aa of the PhaE protein were missing in both strains. The amino acids deduced from the 


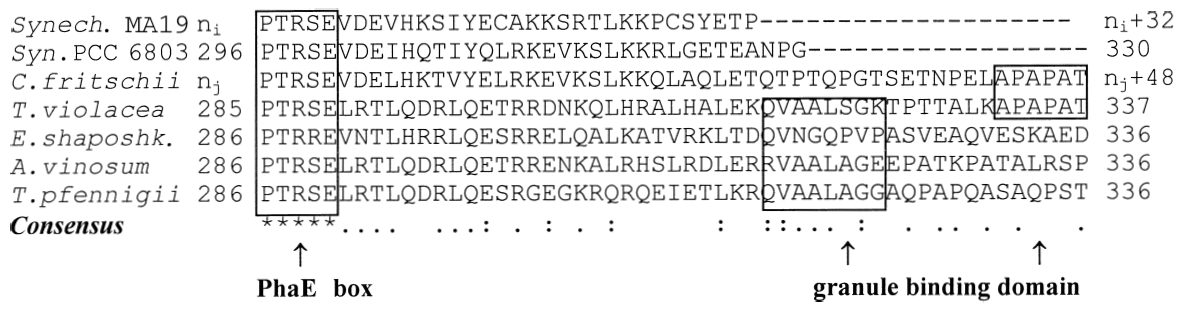

Fig. 4. Alignment of the C-terminal amino acid sequences encoded by various phaE genes. The sequences of Synechococcus sp. MA19 and Chlorogloeopsis fritschii PCC 6912, which were determined in this study, were aligned with those of Synechocystis sp. PCC 6803, Allochromatium vinosum, Thiocystis violacea, Thiococcus pfennigii and Ectothiorhodospira shaposhnikovii. The PhaE box shows a region of absolutely identical amino acids occurring among PhaE subunits. The stretches GIn-Val-Ala-Ala-Leu-Ala-Gly and Ala-Pro-Ala-Pro-Ala-Thr occurring in the PhaE proteins of anoxygenic sulfur bacteria, which might be related to PHA granule binding sites (Liebergesell et al., 2000), are boxed for comparison with the corresponding regions in the $\mathrm{PhaE}$ proteins of cyanobacteria. Absolute conservation, high conservation and low conservation are indicated by ' $*$ ' ' ' ' ' and '.$'$, respectively. $n_{\mathrm{i}}$ and $n_{\mathrm{j}}$ are the numbers of amino acids in C-terminal regions of $\mathrm{PhaE}_{\mathrm{MA} 19}$ and $\mathrm{PhaE}_{\mathrm{Cf}}$, respectively.

\footnotetext{
Asp-302 His-303

His -331

$\downarrow \downarrow$

$\downarrow$

A.vinosum 298 FALQDHLVPP DASRALKGLT SS-PDY'TELA FPGGHIGIYV SGKAQKEVTP AIGKWLNER- 355

T.violacea 297 YALQDHLVPP DASKALNPWS AA-RTYTELA FPGGHIGIYV SGKAQKEVTP AIGKWLNERS 355

T.pfennigii 297 YPMQDHLVPP DASKALAGLT SS-EDYTELA FPGGHIGIYV SGKAQEGVTP AIGRWLNERG 355

E.shaposhk. 297 FAEQDHLVPP DASKALAGKV GT-KDYTELS FPGGHIGIYV SGKAQKTVPP AIGKWVKERG 355

SYnech. MA19 306 YAEKDHLVPP RSSIALERYI GT-TDYTVRS FPVGHIGIYV SSKVQRDLPP IIANWLNARE 364

c.fritschii 308 YAEKDHLVPP ASSLALAKYI DT-QDYTAKG FPVGHIGMYV SGKVQRDLPP VIADWLRNRD 366

SYn. PCC 6803319 YAEKDHLVAP ASSLALGDYL PENCDYTVQS FPVGHIGMYV SGKVQRDLPP AIAHWLSERQ 378

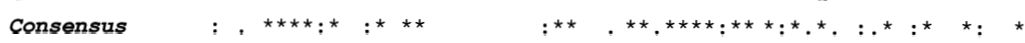

Fig. 5. Alignment of the C-terminal amino acid sequences deduced from phaC from seven strains of cyanobacteria and photosynthetic $\gamma$-Proteobacteria. previously sequenced DNA fragments of $p h a E_{\mathrm{Cf}}$ and phaE $E_{\text {MA19 }}$ exhibited higher similarities to the PhaE proteins of anoxygenic photosynthetic bacteria than did PhaE $_{\text {Syn }}$ to the PhaE proteins of other type-III PHA synthases. However, their C-terminal regions showed no homology to the Gln-Val-Ala-Ala-Leu-Ala-Gly stretch, which is typical of the C-terminal regions of PhaE proteins of the photosynthetic $\gamma$-Proteobacteria (Fig. 4). This stretch has been suggested to act as the binding site of the PHA synthase complex to the PHA granule surface of these bacteria (Liebergesell et al., 2000). It is remarkable that the C-terminal region of $\mathrm{PhaE}_{\mathrm{Cf}}$ exhibited a unique Ala-Pro-Ala-Pro-Ala-Thr stretch, which is identical to that of Thiocystis violacea (Fig. 4) and is related to other binding sites of phasin proteins (Liebergesell et al., 2000).

\section{Comparison of cyanobacterial PHA synthases with PHA synthases from other bacteria}

PCR products from the $p h a C$ upstream and downstream regions of Synechococcus sp. MA19 (phaC $\left.\mathrm{MA19}_{19}\right)$ and Chlorogloeopsis fritschii PCC $6912 \quad\left(p h a C_{\mathrm{Cf}}\right)$ were obtained, ligated into $\mathrm{pSK}^{-}$, transformed into Escherichia coli XL-1 Blue and sequenced. Comparison of the amino acid sequences deduced from $p h a C_{\mathrm{MA} 19}$ (364 aa) and $p h a C_{\mathrm{Cf}}$ (366 aa) with the primary structures of proteins in the NCBI database revealed the following similarities to other PHA synthases: $\mathrm{PhaC}_{\mathrm{MA19}}$ exhibited identities of $74,67,58,55,54$ and $52 \%$ to the $\mathrm{PhaC}$ proteins of Chlorogloeopsis fritschii PCC 6912, Synechocystis sp. PCC 6803, Ectothiorhodospira shaposhnikovii, Thiocystis pfennigii, Allochromatium vinosum and Thiocystis violacea, respectively; $\mathrm{PhaC}_{\mathrm{Cf}}$ exhibited identities of $71,53,53,53$ and $52 \%$ to the PhaC proteins of the same five strains, respectively.

The high level of similarity among these sequences confirms the high level of conservation of these PhaC regions, from which the universal phaC screening primers, Haphapcr1 and Haphapcr2, were deduced and degenerated. However, the amino acid sequences deduced from $\mathrm{PhaC}_{\mathrm{MA19}}$ and $\mathrm{PhaC}_{\mathrm{Cf}}$ also exhibited highly conserved regions adjacent to the positions corresponding to Cys-149, Asp-302, His-303 and His-331 in the sequence of Allochromatium vinosum. These residues are important for activation of the 3-hydroxylalkyl moiety of 3-hydroxybutyryl-CoA (Asp-302, His-303) and nucleophilic attack (His-331) (Fig. 5), as well as for covalent catalysis carried out at Cys-149 (Jia et al., 2000; see also Fig. 2). In addition to the results shown above, about 180 aa could be deduced from the phaCspecific PCR product obtained from Cyanothece sp. PCC $8303\left(\mathrm{PhaC}_{\mathrm{C} . \mathrm{sp}}\right)$. This partial gene sequence was also aligned with all PhaC proteins of type-III PHA synthases using the CLUSTAL w program. The amino acid sequences at the covalent catalysis site of PhaC of both thermophilic cyanobacteria and the mesophilic cyanobacterium Cyanothece sp. PCC 8303 also reveal striking similarities to the active centres of lipases, which exhibit a mechanism of catalysis similar to that of PHA 


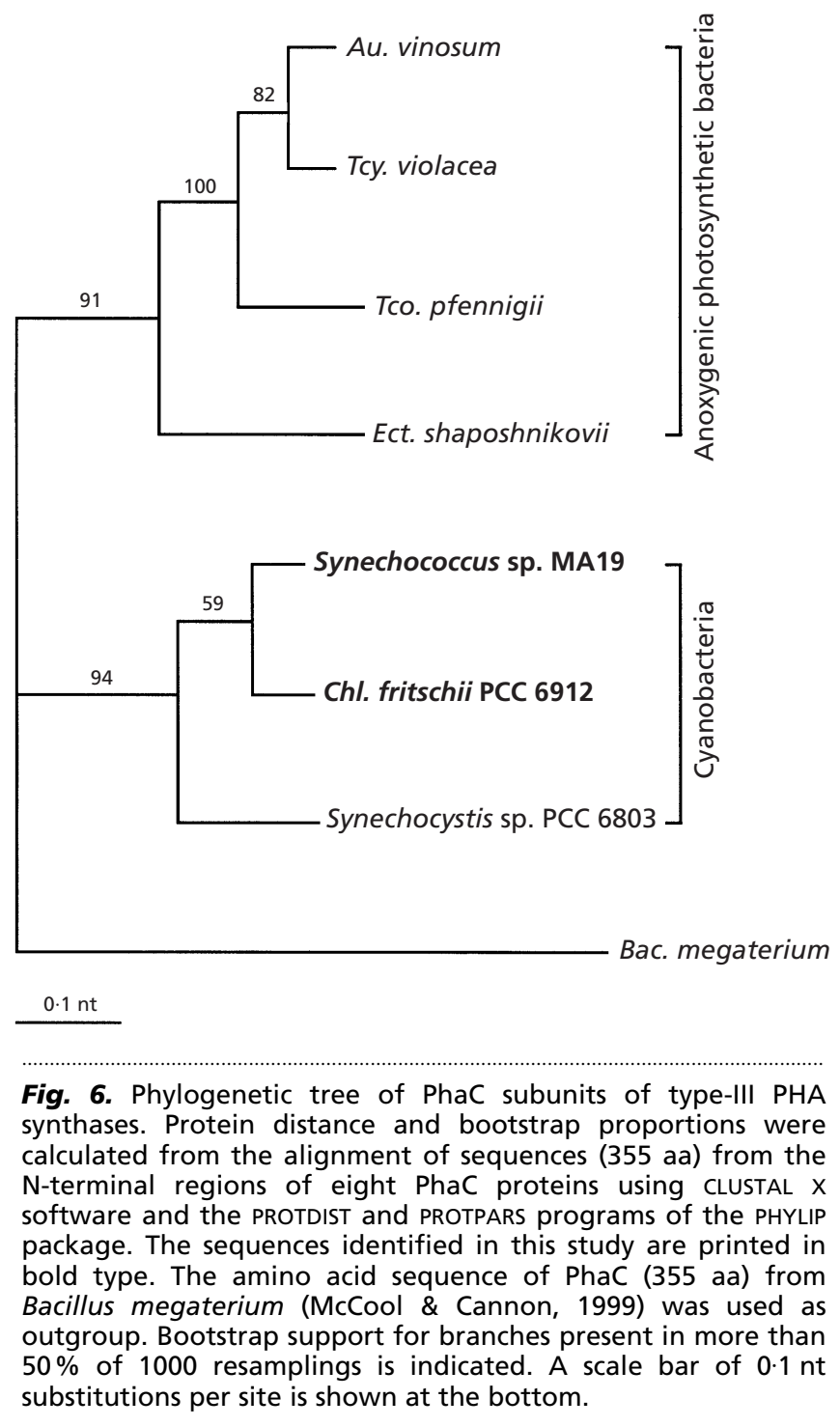

synthases (Liebergesell \& Steinbüchel, 1993; Jia et al., 2000).

Distance matrices were calculated using the PHYLIP program package (Felsenstein, 1989). On the basis of PROTDIST and PROTPARS analyses a phylogenetic tree was generated from each of the three PhaC sequences of cyanobacteria (Synechocystis sp. PCC 6803, Synechococcus sp. MA19, Chlorogloeopsis fritschii PCC 6912) and anoxygenic photosynthetic $\gamma$-Proteobacteria (Thiococcus pfennigii, Allochromatium vinosum, Thiocystis violacea and Ectothiorhodospira shaposhnikovii). Bacillus megaterium $\mathrm{PhaC}$ was used as outgroup. In the cyanobacterial subgroup, PhaC of Synechocystis sp. PCC 6803 separated from the PhaC proteins of the two thermophilic strains Synechococcus sp. MA19 and Chlorogloeopsis fritschii PCC 6912. In the anoxygenic photosynthetic bacteria subgroup $\mathrm{PhaC}$ of Ectothiorhodospira shaposhnikovii was separated from the PhaC proteins of Thiococcus pfennigii, Thiocystis violacea and Allochromatium vinosum (Fig. 6).

\section{Co-expression of $p h a C_{\mathrm{MA} 19}$ or phaC $\mathrm{Cf}_{\mathrm{Cf}}$ with phaA and phaB of Synechocystis sp. PCC 6803}

It has been reported previously that functionally active poly $(3 \mathrm{HB})$ biosynthesis pathways relying on type-III PHA synthases are heterologously expressed in Escherichia coli only if both subunits PhaE and PhaC from one strain (Hein et al., 1998; Taroncher-Oldenburg et al., 2000) or from two different strains (Liebergesell et al., 2000) are co-expressed together with phaA and phaB, encoding $\beta$-ketothiolase and acetoacetyl-CoA reductase, respectively, from $R$. eutropha or from Synechocystis sp. PCC 6803. The corresponding recombinant strains of Escherichia coli accumulated poly $(3 \mathrm{HB})$ amounting to $13 \%(\mathrm{w} / \mathrm{v})$ of CDM when the cells were cultivated in LB medium containing $1 \%$ $(\mathrm{w} / \mathrm{v})$ glucose. In the case of the PHA synthase of Allochromatium vinosum, the enzyme was only active if both subunits $\mathrm{PhaC}$ and $\mathrm{PhaE}$ were co-expressed with PhaA and PhaB (Liebergesell et al., 1994; Müh et al., 1999). Since the phaE-phaC intragenic regions in the genomes of Synechococcus sp. MA19 and Chlorogloeopsis fritschii PCC 6912 are longer than in other bacteria possessing type-III PHA synthases, $p h a C_{\text {MA19 }}$ and $p h a C_{\mathrm{Cf}}$ were co-expressed together with $p h a A-B_{\mathrm{Syn}}$ in Escherichia coli XL-1 Blue to investigate whether PhaC from both strains conferred PHA synthase activity in vivo as well as in vitro. A recombinant strain of Escherichia coli harbouring the hybrid plasmid pSK $A B C_{\text {MA19 }}$ (Fig. 7), in which phaAB $B_{\text {Syn }}$ was located downstream of $p h a C_{\mathrm{MA} 19}$ and in co-linear orientation to the lacZp/o, exhibited an in vitro activity of $0.8 \mathrm{U}(\mathrm{mg}$ protein $)^{-1}$, whereas cells harbouring plasmid pSKAB $B_{\text {Syn }}$ (Fig. 7) exhibited a residual activity of only $0.45 \mathrm{U}$ (mg protein $)^{-1}$. Using a similar construction for $\mathrm{PhaC}_{\mathrm{Cf}}$, a specific PHA synthase activity of $1 \cdot 1 \mathrm{U}$ (mg protein) ${ }^{-1}$ was measured with pSKABC $C_{\mathrm{Cf}}$ (Fig. 7). As a positive control the PHA synthase in pSKABEC $C_{\text {Syn }}$ exhibited about $10 \mathrm{U}$ (mg protein) ${ }^{-1}$ (Table 5). The recombinant cells harbouring pSKABC $C_{\mathrm{MA} 19}$ or $\mathrm{pSK} A B C_{\mathrm{Cf}}$ accumulated poly $(3 \mathrm{HB})$ amounting to 2 and $1.5 \%(\mathrm{w} / \mathrm{w})$ of CDM, respectively, if grown in LB containing $0.6 \%$ $(\mathrm{w} / \mathrm{v})$ glucose, $0 \cdot 2 \mathrm{mM}$ IPTG and $50 \mu \mathrm{M}$ thiamine. The methanolized substances from the cells harbouring the control plasmid $\mathrm{pSK} A B_{\mathrm{Syn}}$ and grown under the same conditions also contained a $3 \mathrm{HB}$ peak amounting to $0 \cdot 8 \%(\mathrm{w} / \mathrm{w})$ of CDM and most probably representing monomers of $3 \mathrm{HB}$. In the absence of IPTG, the poly $(3 \mathrm{HB})$ content of the cells was only $0 \cdot 2 \%(\mathrm{w} / \mathrm{w})$ of CDM (Table 5). These experiments demonstrated that phaC of the investigated cyanobacteria alone is able to confer low but significant residual PHA synthase activity and poly $(3 \mathrm{HB})$ synthesis to Escherichia coli in the absence of phaE. However, this only occurred if $\beta$ ketothiolase (PhaA) and acetoacetyl CoA reductase (PhaB) were also expressed. It should be noted that it has been shown that the purified $\mathrm{PhaC}$ protein of Allochromatium vinosum exhibited approximately $0.6 \%$ residual PHA synthase activity of the intact PHA synthase consisting of $\mathrm{PhaE}$ plus $\mathrm{PhaC}$ (Müh et al., 1999). This is significantly less than the PHA synthase 


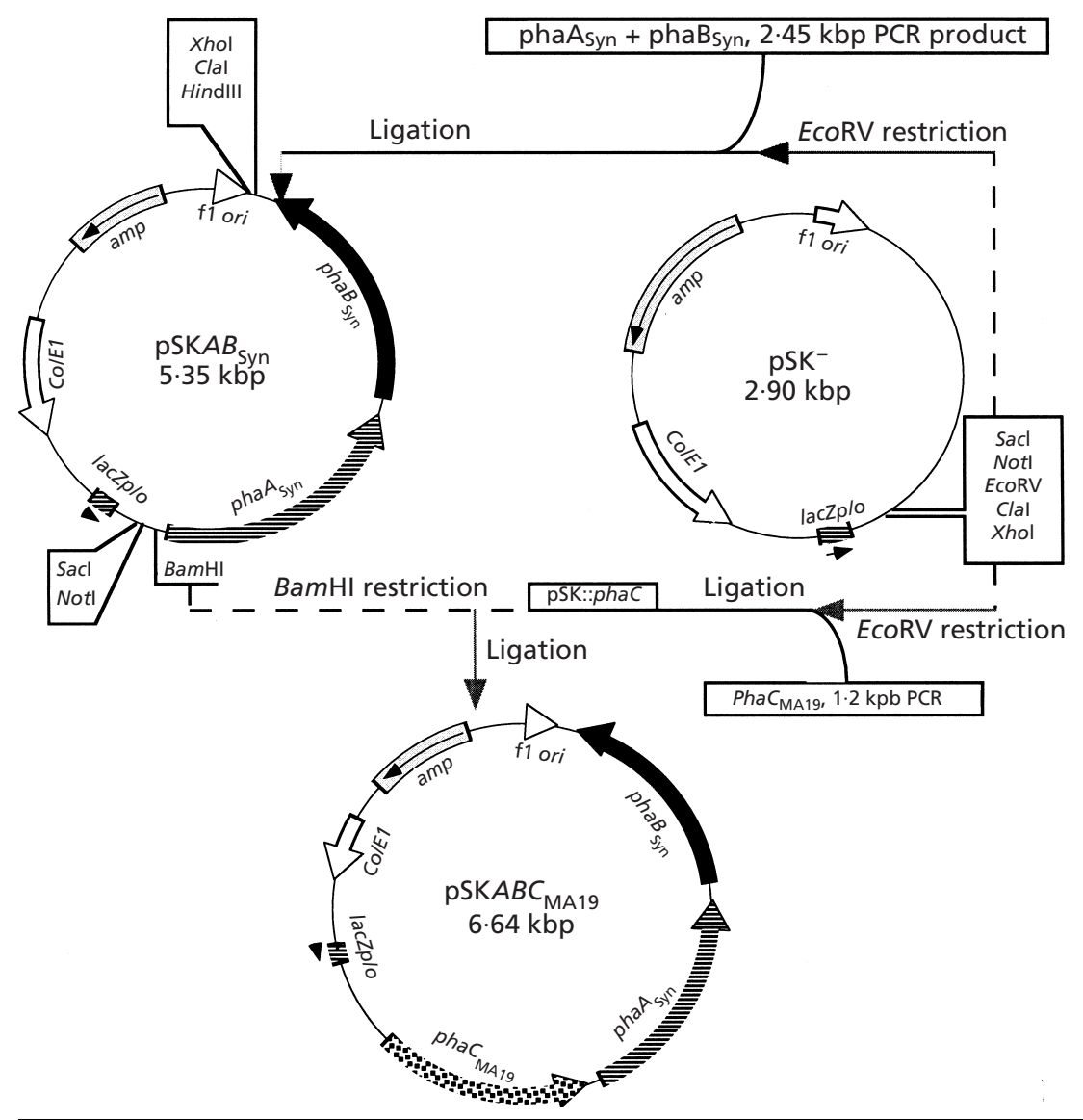

Fig. 7. Construction of hybrid plasmid pSKABC ${ }_{\mathrm{MA19}}$ for investigating the in vitro activity of $\mathrm{PhaC}_{\mathrm{MA} 19}$ by co-expression with $\mathrm{PhaA}_{\text {Syn }}$ and PhaB $\mathrm{Pyn}_{\text {Syn }}$ of Synechocystis sp. PCC 6803. A similar construct was made to obtain the corresponding plasmids $\mathrm{pSK} A B C_{\mathrm{Cf}}$

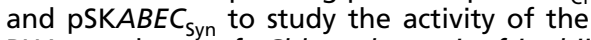
PHA synthase of Chlorogloeopsis fritschii PCC 6912 and as a positive control, respectively.

Table 5. PHA accumulation and in vitro PHA synthase activity of recombinant strains of Escherichia coli

ND, Not detectable; NA, not analysed.

\begin{tabular}{|c|c|c|c|c|}
\hline Strain (plasmid) & Relevant markers & IPTG $(0 \cdot 2 \mathrm{mM})$ & $\begin{array}{c}\operatorname{Poly}(3 \mathrm{HB}) \\
(\%, \mathrm{w} / \mathrm{w}, \text { of } \mathrm{CDM})\end{array}$ & $\begin{array}{c}\text { Specific activity } \\
{\left[\mathrm{U}(\mathrm{mg} \text { protein })^{-1}\right]^{*}}\end{array}$ \\
\hline $\begin{array}{l}\text { Escherichia coli } \\
\text { XL-1 Blue }\end{array}$ & See Table 1 & - & ND & ND \\
\hline $\mathrm{pSK}^{-}$ & See Table 1 & + & ND & $<0 \cdot 10$ \\
\hline $\mathrm{pSKC}_{\mathrm{MA}}$ & phaC $\mathrm{MA19}^{+}$ & + & ND & $<0 \cdot 10$ \\
\hline $\mathrm{pSKC}_{\mathrm{Cf}}$ & $\mathrm{phaC}_{\mathrm{Cf}}^{+}$ & + & ND & $<0 \cdot 10$ \\
\hline $\mathrm{pSKAB}_{\mathrm{Syn}}$ & $p h a A_{\mathrm{Syn}}^{+} p h a B_{\mathrm{Syn}}^{+}$ & + & $0 \cdot 8 \pm 0 \cdot 4$ & $0 \cdot 45 \pm 0 \cdot 15$ \\
\hline $\mathrm{pSKABC}_{\mathrm{MA}}$ & $p h a A_{\mathrm{Syn}}{ }^{+} p h a B_{\mathrm{Syn}}{ }^{+} p h a C_{\mathrm{MA} 19^{+}}{ }^{+}$ & + & $2 \cdot 0 \pm 0 \cdot 1$ & $0 \cdot 80 \pm 0 \cdot 05$ \\
\hline $\mathrm{pSKABC}_{\mathrm{MA}}$ & $p h a A_{\mathrm{Syn}}{ }^{+} p h a B_{\mathrm{Syn}}{ }^{+} p h a C_{\mathrm{MA} 19}{ }^{+}$ & - & $0 \cdot 2 \pm 0 \cdot 1$ & NA \\
\hline $\mathrm{pSKABC}_{\mathrm{Cf}}$ & $p h a A_{\mathrm{Syn}}^{+}{ }^{+} p h a B_{\mathrm{Syn}}^{+} p h a C_{\mathrm{Cf}}^{+}$ & + & $1 \cdot 5 \pm 0 \cdot 2$ & $1 \cdot 1 \pm 0 \cdot 10$ \\
\hline pSKABEC $_{\mathrm{Syn}}$ & $p h a A_{\mathrm{Syn}}{ }^{+} p h a B_{\mathrm{Syn}}^{+} p h a E_{\mathrm{Syn}}{ }^{+}$and $p h a C_{\mathrm{Syn}}{ }^{+}$ & + & $43 \cdot 0 \pm 1 \cdot 5$ & $10 \cdot 0 \pm 0 \cdot 50$ \\
\hline
\end{tabular}

*One unit $(\mathrm{U})$ is defined as $1 \mu \mathrm{mol}$ substrate [D-(-)-3-hydroxybutyryl-CoA] $\mathrm{min}^{-1}$.

activity conferred to Escherichia coli by the cyanobacterial PhaC proteins investigated in this study.

\section{Conclusions}

The cyanobacterial strains investigated in this study accumulated PHA only in the presence of acetate. Under these mixotrophic growth conditions $3 \mathrm{HB}$ was the only constituent of the accumulated polyester. Multiple evidence was obtained that biosynthesis of poly $(3 \mathrm{HB})$ in the investigated cyanobacteria is due to a type-III PHA synthase. Evidence for this was obtained by Southern blot analysis using type-III PhaC-specific DNA probes, Western blot analysis using specific anti-PhaE $\mathrm{Syn}_{\mathrm{Snti}}$ an bodies, PCR techniques using phaC-specific oligomers as primers and by cloning and DNA sequence analysis of 
the PHA synthase structural genes from three different cyanobacteria. Together with the data obtained previously for the PHA synthase of Synechocystis sp. PCC 6803 (Kaneko et al., 1996; Hein et al., 1998) and considering the phylogenetic positions of the cyanobacteria, investigated with respect to the molecular and biochemical basis of poly $(3 \mathrm{HB})$ biosynthesis, it can be concluded that type-III PHA synthase is probably the characteristic PHA synthase of cyanobacteria in general.

\section{ACKNOWLEDGEMENTS}

The authors thank Dr Rippka (Institut Pasteur, Paris, France) for providing axenic cultures of 10 cyanobacterial strains (Table 1) and Drs Miyake and Asada (Molecular Laboratory, National Institute of Bioscience and Human-Technology, Tsukuba, Ibaraki, Japan) for providing Synechococcus sp. MA19. This study was supported by a grant of the Bundesministerium für Landwirtschaft und Forsten, KZ: 95NR048-F (Berlin, Germany).

\section{REFERENCES}

Arino, X., Ortega-Calvo, J. J., Hernandez-Marine, M. \& SainzJimenez, C. (1995). Effect of sulfur starvation on the morphology and ultrastructure of the cyanobacterium Gloeothece sp. PCC 6909. Arch Microbiol 163, 447-453.

Bradford, M. M. (1976). A rapid and sensitive method for the quantitation of microgram quantities of protein utilizing the principle of protein-dye binding. Anal Biochem 72, 248-254.

Carr, N. G. (1966). The occurrence of poly- $\beta$-hydroxybutyrate in the blue-green alga, Chlorogloea fritschii. Biochim Biophys Acta 120, 22308-22310.

De Philippis, R., Sili, C. \& Vincenzini, M. (1992). Glycogen and poly- $\beta$-hydroxybutyrate synthesis in Spirulina maxima. J Gen Microbiol 138, 1623-1628.

Felsenstein, J. (1989). PHYLIP - phylogeny inference package (version 3.2). Cladistics 5, 164-166.

Hai, T., Oppermann-Sanio, F. B. \& Steinbüchel, A. (1999). Purification and characterization of cyanophycin and cyanophycin synthetase from the thermophilic Synechococcus sp. MA19. FEMS Microbiol Lett 181, 229-236.

Hein, S., Hai, T. \& Steinbüchel, A. (1998). Synechocystis sp. PCC 6803 possesses a two-component polyhydroxyalkanoic acid synthase similar to that of anoxygenic purple sulfur bacteria. Arch Microbiol 170, 162-170.

Hjelm, H., Hjelm, K. \& Sjöquist, J. (1972). Protein A from Staphylococcus aureus. Its isolation by affinity chromatography and its use as an immunosorbant for isolation of immunoglobulins. FEBS Lett 28, 73-76.

Hoang, T. T. \& Schweizer, H.P. (1999). Characterization of Pseudomonas aeruginosa enoyl-acyl carrier protein reductase (FabI) : a target for the antimicrobial triclosan and role in acylated homoserine lactone synthesis. J Bacteriol 181, 5489-5497.

Jensen, T. E. \& Sicko, L. M. (1971). Fine structure of poly- $\beta$ hydroxybutyric acid granules in a blue-green alga, Chlorogloea fritschii. J Bacteriol 111, 683-686.

Jia, J., Kappock, J., Frick, T., Sinskey, A. J. \& Stubbe, J. (2000). Lipase provides a new mechanistic model for polyhydroxybutyrate synthases: Characterization of the functional residues in Chromatium vinosum PHB synthase. Biochemistry 39, 3927-3936.

Kaneko, T., Sato, S., Kotani, H. \& 21 other authors (1996).
Sequence analysis of the genome of the unicellular cyanobacterium Synechocystis sp. strain PCC 6803. II. Sequence determination of the entire genome and assignment of potential protein-coding regions (supplement). DNA Res 30, 185-209.

Laemmli, U. K. (1970). Cleavage of structural proteins during the assembly of the head of bacteriophage T4. Nature 227, 680-685.

Lama, L., Nicolaus, B., Calandrelli, M., Manca, M. C., Romano, I. \& Gambacorta, A. (1996). Effect of growth conditions on endo- and exopolymer biosynthesis in Anabaena cylindrica 10C. Phytochemistry 42, 655-659.

Liebergesell, M. \& Steinbüchel, A. (1992). Cloning and nucleotide sequence of genes relevant for biosynthesis of polyhydroxyalkanoic acid in Chromatium vinosum strain D. Eur J Biochem 209, 135-150.

Liebergesell, M. \& Steinbüchel, A. (1993). Cloning and molecular analysis of the poly(3-hydroxybutyric acid) biosynthesis genes of Thiocystis violacea. Appl Microbiol Biotechnol 38, 493-501.

Liebergesell, M., Sonomoto, K., Madkour, M., Mayer, F. \& Steinbüchel, A. (1994). Purification and characterization of the poly(hydroxyalkanoic acid) synthase from Chromatium vinosum and localization of the enzyme at the surface of poly(hydroxyalkanoic acid) granules. Eur J Biochem 226, 71-80.

Liebergesell, M., Rahalkar, S. \& Steinbüchel, A. (2000). Analysis of the Thiocapsa pfennigii polyhydroxyalkanoate synthase: subcloning, molecular characterization and generation of hybrid synthases with the corresponding Chromatium vinosum enzyme. Appl Microbiol Biotechnol 54, 186-194.

McCool, G. J. \& Cannon, M. C. (1999). Polyhydroxyalkanoate inclusion body-associated proteins region in Bacillus megaterium. J Bacteriol 181, 585-592.

Miyake, M., Erata, M. \& Asada, Y. (1996). A thermophilic cyanobacterium, Synechococcus sp. MA19, capable of accumulating poly- $\beta$-hydroxybutyrate. J Ferment Bioeng 82, 512-514.

Müh, U., Sinskey, A. J., Kirby, D. P., Lane, W. S. \& Stubbe, J. A. (1999). PHA synthase from Chromatium vinosum: Cysteine 149 is involved in covalent catalysis. Biochemistry 38, 826-837.

Rehm, B. H. A. \& Steinbüchel, A. (1999). Biochemical and genetic analysis of PHA synthases and other proteins required for PHA synthesis. Biol Macromol 25, 3-19.

Rippka, R., Nelson, A., Kunisawa, R. \& Cohen-Bazire, G. (1971). Nitrogen fixation by unicellular blue-green algae. Arch Mikrobiol 76, 341-348.

Rippka, R., Deruelles, J., Waterbury, J. B., Herdman, M. \& Stanier, R. Y. (1979). Genetic assignments, strain histories and properties of pure cultures of cyanobacteria. J Gen Microbiol 111, 1-61.

Sambrook, J., Fritsch, E. F. \& Maniatis, T. (1989). Molecular Cloning: a Laboratory Manual, 2nd edn. Cold Spring Harbor, NY : Cold Spring Harbor Laboratory.

Simon, R., Priefer, U. \& Pühler, U. (1983). A broad host range mobilization system for in vivo engineering: transposon mutagenesis in gram negative bacteria. Biotechnology 1, 784-791.

Stal, L. J., Heyer, H. \& Jacob, G. (1990). Occurrence and role of polyhydroxyalkanoate in the cyanobacterium Oscillatoria limosa. In Novel Biodegradable Microbial Polymers, pp. 435-438. Edited by E. A. Dawes. Dordrecht: Kluwer.

Steinbüchel, A. (2001). Perspectives for biotechnological production and utilization of biopolymers: Metabolic engineering of polyhydroxyalkanoate biosynthesis pathways as a successful example. Macromol Biosci 1, 1-24.

Steinbüchel, A. \& Hein, S. (2001). Biochemical and molecular basis of polyhydroxyalkanoic acids in microorganisms. Adv Biochem Eng Biotechnol 71, 81-123. 
Steinbüchel, A. \& Valentin, H. E. (1995). Diversity of bacterial polyhydroxyalkanoic acids. FEMS Microbiol Lett 128, 219-228.

Taroncher-Oldenburg, G., Nishina, K. \& Stephanopoulos, G. (2000). Identification and analysis of the polyhydroxyalkanoatespecific $\beta$-ketothiolase and acetoacetyl coenzyme A reductase genes in the cyanobacterium Synechocystis sp. strain PCC 6803. Appl Environ Microbiol 66, 4440-4448.

Timm, A., Byrom, D. \& Steinbüchel, A. (1990). Formation of blends of various poly(3-hydroxyalkanoic acids) by a recombinant strain of Pseudomonas oleovorans. Appl Microbiol Biotechnol 33, 296-301.

Triglia, T., Peterson, M. G. \& Kemp, D. J. (1988). A procedure for in vitro amplification of DNA segments that lie outside the boundaries of known sequences. Nucleic Acids Res 16, 8186.

Valentin, H. E. \& Steinbüchel, A. (1994). Application of enzymatically synthesized short-chain-length hydroxy fatty acid coenzyme A thioesters for assay of polyhydroxyalkanoic acid synthases. Appl Microbiol Biotechnol 40, 699-709.

Vincenzini, M. \& De Philippis, R. (1999). Polyhydroxyalkanoates. In Chemicals from Microalgae, pp. 292-312. Edited by Z. Cohen. London: Taylor \& Francis.

Vincenzini, M., Sili, C., De Philippis, R., Ena, A. \& Materasi, R. (1990). Occurrence of poly- $\beta$-hydroxybutyrate in Spirulina species. J Bacteriol 172, 2791-2792.

Weber, K. \& Osborn, M. (1969). The reliability of molecular weight determination by sodium dodecyl sulfate-polyacrylamide gel electrophoresis. J Biol Chem 244, 4406-4412.

Received 26 April 2001; revised 6 July 2001; accepted 25 July 2001. 